\title{
Drug Safety Governance: Framework and Development Path
}

\author{
Yanjiao Zhao',2, Lin Wu ${ }^{1,2}$, Xinxin Wang1,2, Yongfa Chen ${ }^{1,2^{*}}$ \\ ${ }^{1}$ The Research Center of National Drug Policy \& Ecosystem, China Pharmaceutical University, Nanjing, China \\ ${ }^{2}$ Institute of Regulatory Science, China Pharmaceutical University, Nanjing, China \\ Email: zyj15110@163.com, cpu_wlsxy@163.com,2554527141@qq.com, *cyf990@163.com
}

How to cite this paper: Zhao, Y. J., Wu, L. Wang, X. X., \& Chen, Y. F. (2021). Drug Safety Governance: Framework and Development Path. Journal of Service Science and Management, 14, 541-556. https://doi.org/10.4236/jssm.2021.146034

Received: November 1, 2021

Accepted: November 29, 2021

Published: December 2, 2021

Copyright (c) 2021 by author(s) and Scientific Research Publishing Inc. This work is licensed under the Creative Commons Attribution International License (CC BY 4.0).

http://creativecommons.org/licenses/by/4.0/

\section{(c) (i) Open Access}

\begin{abstract}
Objective: The necessity of shifting from management to governance of drug safety has gained a wide consensus in both academic and practical circles, but how to act and develop has not been adequately discussed and become a key issue that needs to be addressed nowadays. This article combines the theoretical essence of governance to establish an analytical framework of "initial conditions-joint action-governance effectiveness" based on governance theory to analyze and explain the connotation and mechanism of cross-sector cooperative governance of drug safety. Methods: The essence of governance lies in the creation of joint action capabilities through cross-sector cooperation, as well as the construction of a national drug safety governance action framework of " 3 stages +1 incubation period". This article analyzes the connotation of each stage and possible problems or obstacles. Results: Three deepseated challenges stem from the lack of information sharing, resource action sharing, and power sharing. Conclusion: In order to improve the modernization construction of China's drug safety governance system and capacity, it is recommended to continuously improve Chinese drug safety governance in terms of governance norms, communication mechanisms, capacity development, and cross-sector coordination based on a holistic perspective.
\end{abstract}

\section{Keywords}

Drug Safety Governance, Cross-Sector Cooperation, Collaborative Governance, Governance Modernization

\section{Introduction}

In the century-long history of drug regulation in human society, the reform of drug safety regulatory system has almost always been problem-driven (Yang, 
2017). In both developing and developed countries, after experiencing three major problem periods: inadequate supply of medicines, increased threat of technical risks and intensive outbreaks of emergencies, they have now entered a crucial period for building a more open and transparent drug safety governance system with the participation of multiple subjects. In order to improve the quality and reputation of medicines in China and to build a long-term drug safety regulatory system and mechanism, a common goal-oriented governance model, which does not involve government authority, is promptly becoming the ideal solution to such complex cross-sector public issues as drug safety.

There has been a significant shift from government centric authoritarian regulation to a governance paradigm. The importance of non-government subjects such as enterprises, social organizations and the public in improving the effectiveness of drug safety governance is increasingly recognized (Hu \& Lin, 2017). But internal government construction, such as the fragmentation of the regulatory system, will not be automatically solved by the participation of the private sector ${ }^{1}$. At the same time, the equity and transparency of private sector participation in governance require corresponding guidance and control mechanisms. As a new type of policy tool, governance is not a simple combination of labor elements, let alone an infinite increase in quantity. The key to governance is the coordination and integration of a range of cross-sector elements to produce desired outcomes that could not be achieved by each party acting independently (Himmelman, 1994). This requires not only unity of purpose and awareness among the various governance entities, but also clear behavioral planning, such as developing clear procedures or institutional arrangements (Milward \& Provan, 2006), sharing knowledge and resources (Agranoff, 2007; Thomson \& Perry, 2006), and fostering multiple leadership roles (Agranoff \& Mcguire, 2004). Regarding the above-mentioned key governance issues, China is still at the initial stages of exploration, both theoretically and practically. Most of the existing researches focus on theoretical descriptions and discussions of the logic and public values of drug safety governance, which are enlightening but fail to reveal the direction and concrete path of drug safety governance reform in China under the new situation. It weakens the application value and influence of the research results. In view of this, the core proposition of this paper is to construct a framework for action on drug safety governance in China based on theory and policy practice, to clarify the key issues or obstacles that should be broken through at different stages of governance and to propose recommendations for improvement.

${ }^{1}$ From the perspective of juridical functional classification, the criterion for judging the public and private nature of an activity should be whether the activity is authorized through laws and regulations. If the subject undertakes administrative tasks, performs administrative duties or governmental functions, it will fall under the public sector; otherwise, it should be included in the private sector. This way of classifying the public and private sectors by the responsibilities and attributes of the subject is also more consistent with the connotation of drug safety governance practices. This paper also opts to include third-party subjects such as corporations and nonprofit organizations in the private sector for discussion. 


\section{Building a Theoretical Framework for Drug Safety Governance in China}

\subsection{Theoretical Mechanism}

As a general term, governance usually refers to the act of governing in the public sector, the private sector or between the public and private sectors. In the context of collective action, governance is defined as "the joint determination of norms and rules to guide individual and collective behavior". According to Agranoff, "governance is about rules and forms of collective decision-making". The mechanism favored by governance is not governmental authority or dictatorship, but rather a self-management network based on shared goals (Agranoff \& Mcguire, 2004). Bryson et al. propose that governance is a set of coordinated oversight activities that facilitate the maintenance of partnerships or institutions (Bryson, Crosby, \& Stone, 2006). Emerson et al. distinguish the two decision-making modes of antagonism and managerialism, stating that governance is "the process and structure of public policy making and management", the core of which lies in the establishment of institutionalized joint decision-making procedures (Emerson, Nabatchi, \& Balogh, 2012). Regardless of how it is expressed, the core of governance is always to go beyond the focus on traditional public administrators or administrative departments. Through formal and clear institutional arrangements, enterprises, social organizations, experts, the public and other diverse subjects are guided to participate in the search for broader forms of cross-sector collaboration to improve the effectiveness of public decision-making and service provision. Such cross-sectoral cooperation is not a simple combination of labor elements, but rather a way of overcoming the limitations of independent action and the potential risk of failure by creating a new capacity to act together (Himmelman, 1994). Since the 1990s, cross-sector collaboration has been advocated abroad to address public management challenges. A review of the United States' achievements in the second half of the last century shows that many of its achievements in food and drug safety, community health, education, and other areas were the joint efforts of local governments, businesses, and nonprofit organizations (Cai, 2015).

Based on the above theories and policy practices, this paper constructs an analytical framework for the governance mechanism of cross-sectoral cooperation on drug safety (Figure 1), and elaborates the mechanisms for transforming cross-sectoral cooperation into drug safety governance effectiveness: 1) Crosssectoral cooperation needs certain starting conditions to provide motivation (The Free Dictionary by Farlex, 2021), such as leaders who initiate and ensure support for governance activities, successful experiences of cooperation, resource scarcity or information asymmetry triggered by interdependence, outcome incentives, etc. The scarcity of drug safety regulatory resources is a common fact in all countries. With the continuous extension of drug production chain and the increasing diversification of consumption in modern society, the difficulty of drug safety risk control will only increase day by day. Regulatory 


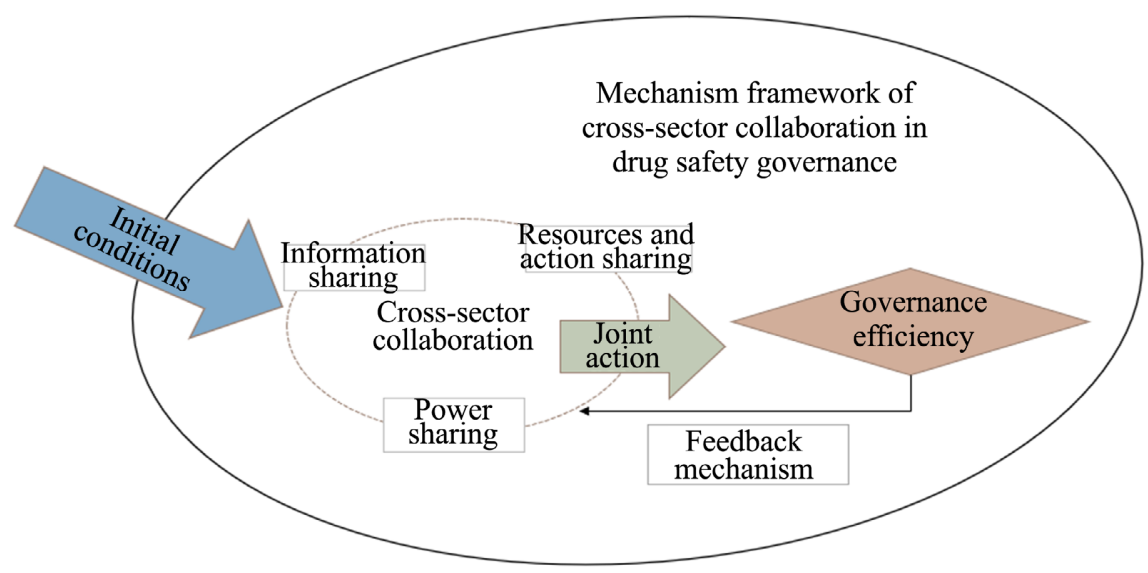

Figure 1. Mechanism framework of cross-sector collaboration in drug safety governance. Source: Rosemary O’Leary, Bingham, and Lisa Blomgren. Big Ideas in Collaborative Public Management, Armonk, NY: M. E. Sharpe, 2008, p.78.

authorities, enterprises, social organizations and the public must fully coordinate and integrate their own resources to jointly cope with it, seeking consensus and reaching a common mission in the process (Guo, 2016). Therefore, formal and informal leaders are required to provide guarantee for governance (Tian, 2013) and enhance the trust relationship between stakeholders so as to encourage the smooth development of cross-sector cooperation activities (Huxham \& Vangen, 2000). 2) Cross-sectoral cooperation in the context of drug safety governance is manifested as a set of shared behavior in a specific institutional environment, including sharing information, views or ideas, resources or actions, authority, etc. (Fierlbeck, 2010). Institutional environment refers to the basic regulations and code of conduct for drug safety management, which can provide justification for cross-sector cooperation and reduce the cooperation conflict, interruption or failure (Tullock, 1980). With the progress and deepening of cooperation, governance subjects will have a sense of belonging to cross-sector cooperation and their degree of mutual understanding and trust will continue to improve. Gradually they will have a new understanding of the relationship between each other. Then become an highly interdependent organic entirety and act together towards the common goal. 3) On the basis of integrating the advantages of individuals and organizations, cross-sectoral cooperation is most likely to create public value if it can find ways to overcome or compensate for the disadvantages of individuals and organizations, which is to produce governance efficiency. These efficiencies are fed back into the process of cross-sectoral cooperation, thus contributing to a virtuous governance cycle.

\subsection{Action Framework: Multi-Stage Drug Safety Governance Model}

From April 2018 to September 2019, this research conducted a qualitative study using semi-structured interview with 18 experienced drug safety governance 
policy formulators and implementers from China to collect information on their perceptions of drug safety governance. The preliminary interview focused on: 1) the composition of China drug safety governance policy system; 2) what historical conditions, political factors, or international commitments influenced the policy formulation process; 3 ) how to ensure the coherence of drug safety governance policies, etc. Besides, combined with the goals and requirements of the 13th Five-Year Plan for National Drug Safety, a drug safety governance analysis framework of "3 stages +1 incubation period" was constructed from the perspective of development (Figure 2), which was designed according to the actual situation and reform needs of China. Both the basic cooperation stage and the "cultivation stage" of legislative coordination stage are preparations for cross-sector cooperation governance of drug safety. Only when there is a sufficient institutional basis and key governance subjects develop the ability to effectively participate in cross-sector cooperation activities, cooperative governance will have the premise of legitimacy and equality.

China's drug safety governance is different from the inherent spirit of openness and cooperation in democratic and constitutional states such as the United States and the United Kingdom, and it is also different from Japan's good tradition of industry self-discipline. China's drug safety governance is confronted with complex factors not faced by foreign countries, including an unregulated order of production and distribution, the relative lack of credit environment, a lagging awareness of corporate responsibility and a fragmented regulatory system. In the historical structure of "strong government-weak society", social autonomy is weak but government capacity is relatively strong. In the early stage of drug safety governance reform, there is a more prominent demand for improving the transparency of government decision-making, which should focus on expanding the scope of information sharing and providing opportunities for non-governmental subjects to "experience" governance. This stage of governance, in which information sharing is the main tool and non-government actors are brought in to cooperate with government action, is referred as the "basic collaboration stage" in this paper.

The drug safety governance system is huge and complex. The governance model based on "experiential" participation and lacking the support of legal system is not sustainable. When the degree of government openness and the

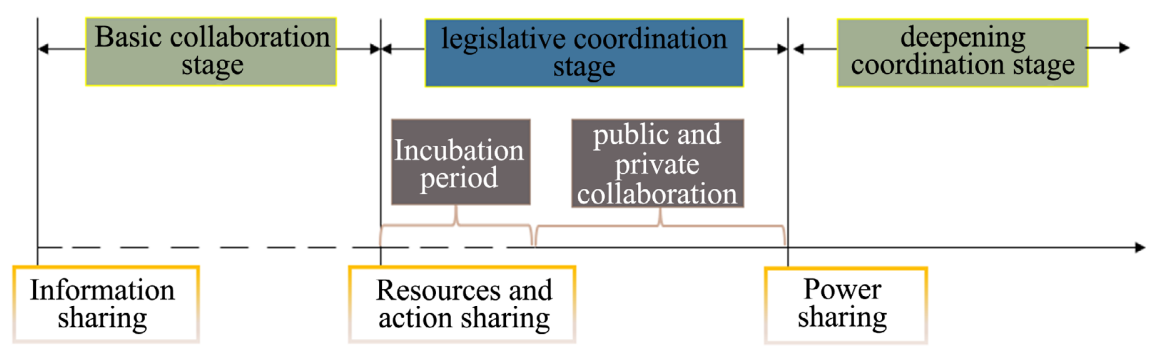

Figure 2. Development path of drug safety governance model in China. Source: based on expert interviews. 
awareness of civil society's self-governance are significantly improved, the collaboration mode based on vertical absorption will no longer be applicable. It is necessary to pay more attention to the two-way cultivation of non-governmental governance capacity and government leadership, which reflects the coordination between self-governance and external supervision. In this period, the demand for the in-depth integration of market, society and government sectors will be more prominent. It's essential to focus on the supply of formal legal systems, promote the orderly sharing of resources and actions between the public and private sectors, and enable non-governmental forces to play their necessary role in public administration and social services. However, if the non-governmental subject develops slowly or fails to meet the requirements of participating in governance, it may need the government to cultivate its growth through role embedding, providing direct resources and policy support. Supported by the legal system, this kind of governance involves the formal and long-term interaction between public and private sectors around specific goals, which is called the "legislative coordination stage" in this paper.

The ideal cooperative governance relationship implies fuzzy boundaries and complex intertwined interactions of multiple subjects. Due to the influence of the centralized management system, it is easy to exclude the public as a legitimate subject of governance in the management of public affairs in China. Therefore, the "deepening coordination" stage should focus more on formal public participation and social supervision mechanisms, in order to break the trust and cooperation dilemma caused by the historical shortcomings of insufficient regulation and power imbalance, and to promote the integration of a wider range of stakeholders in terms of concepts, actions and power structures.

\section{Analysis of Constraints in the Various Stages of Development of Drug Safety Governance}

\subsection{Basic Collaboration Stage}

In fact, China is currently at a stage where the maintenance of social order and the improvement of drug safety are seriously threatened by a serious lack of regulatory resources and a low level of social integrity. A radical rebuilding of the governance structure based on these historical problems may not be a good strategy and risks reducing the efficiency of governance resource allocation. Therefore, the focus at this stage should be on solving the "accumulated ills" and doing a good job of in-depth fundamental exploration. Combined with the existing literature, this paper analyses the main issues facing China's drug safety governance reform as follows.

\subsubsection{Seriously Under-Resourced Drug Safety Regulation at the Primary Level}

For a long time, primary drug regulatory authorities in China have been faced with a shortage of office space, law enforcement facilities and law enforcement equipment, drug safety informatization construction and public service level 
lagging behind seriously, and it is difficult to effectively participate in drug safety information sharing (Dai, 2013). The data from the 2012 Food and Drug Administration Statistics Annual Report show that the rates of equipping special vehicles for law enforcement and rapid drug testing vehicles in primary pharmaceutical supervision agencies are only $7.5 \%$ and $4.5 \%$ respectively. The rate of equipping instruments and equipment at the grassroots level is even smaller. After the institutional reform in 2018, drug regulatory authorities were only set up at the provincial level, and the supervision of drug circulation in cities and counties was assumed by market regulatory departments. Although this shift from "professional regulation" to "integrated regulation" has increased the flexibility of regulatory resource allocation and helped improve enforcement efficiency in the long run, there is also a risk that the increased workload of the primary market regulators will dilute the investment of regulatory resources in the drug sector, even leading to disruption and disorganization in primary drug supervision.

\subsubsection{Public Risk Perception Bias Caused by Poor Risk Communication Is Common in Drug Safety Emergencies}

Due to insufficient social participation, the public, who are already in a disadvantaged position in terms of information, find it difficult to understand the original intention of the formulation and implementation of drug safety policies in China, failing to form a correct perception of drug safety risks and drug safety governance. In the event of drug safety emergencies, this often leads to questions about the government regulatory capacity and impartiality, even affecting the effective implementation of emergency management measures. Taking the "Changchun Changsheng vaccine" incident in 2018 as an example, public anger at the companies involved in the case extended to distrust of domestic vaccines and vaccine regulation in China. In a survey on the attitude towards vaccination conducted among 5775 parents in Gansu Province, 13.85\% of respondents said they are unwilling to continue receiving rabies vaccines. $38.29 \%$ of respondents believed that imported vaccines are safer than domestic vaccines (Liang, Liu, \& Zhang, 2020).

\subsubsection{Structural Contradictions between the Stage of Development of the Pharmaceutical Industry and the Requirements of Integrity}

The key to ensure the safety of medicines is production, not regulation. Ideally, enterprises should take on the role of "the first person responsible for drug safety" to improve drug safety. In fact, China is in a critical period of economic and social transformation. Traditional moral values have been greatly weakened. The contract-based market mechanism is not yet perfect and lacks effective restraint for manufacturers and distributors. Serious drug safety incidents, such as the "Acanthopanax injection", "chromium-exceeding capsules" and "Changchun Changsheng vaccine", have occurred from time to time. The level of integrity of the pharmaceutical industry is incompatible with the level of economic development and the stage of social development in China. There is an urgent need to 
raise the cost of violating the law for pharmaceutical enterprises, and to establish a perfect industry integrity standard and a mechanism for restraining and punishing breach of trust (Sun, 2013).

\subsection{Legislative Coordination Stage}

The key to the formation and maintenance of cross-sector partnerships is the creation of interdependence, based on a clear institutional framework and the ability of stakeholders to participate effectively in governance. The "legislative coordination stage" will be the process of rebuilding a public-private partnership for drug safety from scratch, unlike an administrative commission or a public-private partnership. The key to the success of such public-private partnerships, which are joint actions focused on maximizing the public health interest, lies in the development of laws and rules for collaborative governance through a specific process (Ansell \& Gash, 2008). The construction of a scientific and clear system of drug safety governance is not only to provide social organizations, enterprises, the public and other governance subjects with standardized guidelines (Shen \& Liu, 2017), but also to legitimize the governance powers of public and private sectors, promoting the formation of a close interdependent and supervised relationship between the public and private sectors, achieving substantial sharing of resources and actions. Drawing on foreign experience, most collaborative drug safety governance needs to be based on effective mechanisms for information sharing, joint decision-making and cross-sectoral coordination, which is precisely the main deficiency in the institutional development of China. Based on the construction of relevant governance systems, this paper analyses the possible challenges and logic of the legislative coordination stage.

\subsubsection{Information Sharing Lacks Sufficient Legal Ranking and External Supervision in China}

Information sharing is the foundation of collaborative governance. Imagine if the public has little or no knowledge about government regulation or manufacturing and distribution of pharmaceutical enterprises, then there is no way to talk about collaboration. If the government fails to provide the public with adequate and effective information, then the so-called construction of a service-oriented government is just a magnificent farce (Stiglitz \& Song, 2002). At present, the highest level of government information disclosure law in China is only administrative regulations, People's Republic of China Government Information Disclosure Bill. Compared with the United States, The United Kingdom, Japan and South Korea, the lower legal rank limits its effectiveness (Table 1). The lack of clear definition of the exception rule for information disclosure has inevitably increased the arbitrariness of information disclosure behavior.

\subsubsection{Non-Governmental Demands Are Difficult to Be Adequately} Reflected in the Drug Safety Governance Decision-Making Process

The report of the 19th National Congress of the Communist Party of China 
Table 1. Comparison of sources of information disclosure systems in various countries.

\begin{tabular}{|c|c|c|c|}
\hline Country & $\begin{array}{c}\text { Promulgation } \\
\text { time }\end{array}$ & $\begin{array}{l}\text { The highest } \\
\text { order law }\end{array}$ & Main content \\
\hline China & 2008 & $\begin{array}{c}\text { People's Republic of } \\
\text { China Government } \\
\text { Information } \\
\text { Disclosure Bill }\end{array}$ & $\begin{array}{l}\text { It marks that China's } \\
\text { government information } \\
\text { disclosure has stepped into an } \\
\text { era of "law to follow". }\end{array}$ \\
\hline American & 1966 & $\begin{array}{c}\text { Freedom of } \\
\text { Information Act }\end{array}$ & $\begin{array}{l}\text { It establishes the government's } \\
\text { obligation to disclose } \\
\text { information. Under the guidance } \\
\text { of "disclosure as the principle, } \\
\text { non-disclosure as the exception", } \\
\text { everyone living in the United } \\
\text { States has equal access to all } \\
\text { types of information held by } \\
\text { the government, except in } \\
\text { cases where disclosure is } \\
\text { explicitly stipulated. }\end{array}$ \\
\hline UK & 2000 & $\begin{array}{c}\text { Freedom of } \\
\text { Information Act }\end{array}$ & $\begin{array}{l}\text { It provides public "access" to } \\
\text { information held by regulatory } \\
\text { authorities and gives citizens } \\
\text { the legal right to know whether } \\
\text { certain government information } \\
\text { exists and to obtain it. }\end{array}$ \\
\hline $\begin{array}{l}\text { South } \\
\text { Korea }\end{array}$ & 1996 & $\begin{array}{c}\text { Access to } \\
\text { Information Act }\end{array}$ & $\begin{array}{l}\text { It empowers every national } \\
\text { with the right to request } \\
\text { information disclosure. }\end{array}$ \\
\hline Japan & 1999 & $\begin{array}{c}\text { Access to } \\
\text { Information Act }\end{array}$ & $\begin{array}{l}\text { It mainly makes the rule about } \\
\text { the disclosure of administrative } \\
\text { documents, appeals against, } \\
\text { consultation, information } \\
\text { disclosure review board, the } \\
\text { procedure of review board } \\
\text { investigation meeting and } \\
\text { special cases of litigation } \\
\text { jurisdiction. }\end{array}$ \\
\hline
\end{tabular}

Note: compiled based on information from the official websites of each country.

proposed to "build a social governance pattern of co construction and sharing", encouraging enterprises, social organizations, and the people to actively participate in the construction of the pharmaceutical and health sector. But until now, the participation of the above-mentioned entities has been very limited in the form and scope of drug safety governance. The main focus is on propaganda education and "experiential" enforcement. There is no channel for social resources to intervene in the design of drug safety policies and technical assurance or other specialized work (Zhang, 2017). In addition, the standardization of non-government participation in governance is insufficient. There is a lack of 
systematic planning to ensure the proper and orderly participation of stakeholders in governance, such as Australia's Therapeutic Goods Administration (TGA) Blueprint for the Future and the FDA Advisory Committee on Consumer Representation in the United States.

\subsubsection{Cross-Sector Coordination Issues}

For the supervision of Research and Development (R \& D), registration, manufacturing, distribution, and use of drugs, which is the whole life cycle of drugs, is a joint effort completed by departments of drug evaluation, market, health, industry and information technology, etc. The complex configuration of regulatory functions makes it difficult to maintain the coordination of interdepartmental work. Especially after the new round of institutional reform in 2018, in addition to the reorganization of central ministries' institutions and functions, the configuration of drug safety regulatory authorities has become extremely challenging in local governments and local market regulators. Besides, there is a lack of a strategic coordination framework for public-private cooperation governance. The actions of public and private sectors are inevitably uncoordinated or even contradictory due to different goals and interests. For example, China explicitly prohibits individuals from selling or reselling drugs that are not approved to be marketed in China, so as not to threaten patients' life and health by changing the quality and safety of drugs during transportation and storage. However, the overseas purchase of drugs similar to the Lu Yong case is still a hot phenomenon (Hu, 2014), reflecting the contradiction between enhanced safety regulation and diverse social needs.

\subsection{Deepening Coordination Stage}

There is a bottleneck in the public's ability to participate in the governance of drug safety issues with strong professionalism. Even "professional fake fighters" with a certain degree of expertise are mostly concerned with details such as packaging and labeling, who are unable to identify deep-seated drug safety risks. Therefore, large-scale community participation may not be a good strategy for situations where rapid decision-making or implementation is necessary. Especially when the public doesn't have the capacity to effectively participate in drug safety governance activities yet, an emphasis on openness, democracy, and power sharing may instead reduce governance efficiency. However, it needs to be emphasized that any decision involving public interest must be premised on gaining the understanding and support of the public (Neto, Brandão, \& Cerqueira, 2008). As the drug safety governance has the highest social sensitivity and is fundamental to people's livelihood, the public's attitude and behavior should not be ignored. The role that the public can play in the drug safety governance system will eventually become an important influencing factor for the improvement of governance effectiveness. This paper argues that, after the relatively mature institutional foundation and industry integrity conditions are in place, the "deepening coordination stage" should promote and pay more atten- 
tion to the formal integration of social forces into the governance system. In this case, they can have the power of self-choice in terms of participation ability and path, so as to truly realize the transformation from "passive participation" to self-management. This is an exceptionally complex, time-consuming and resource-intensive process, the fundamental obstacle of which is the weak relationship of trust between our government and society.

Firstly, the political opportunities on which the birth of Chinese society depended on originated from the all-powerful state system established under the leadership of Marxist parties. Modern society emerged only after state power had almost reached its peak, which is completely different from the historical logic of Western capital societies involved in the creation of the state (Fan, 2019). In other words, our society is not the product of its own burgeoning and struggle, but grew up under the policy created by the ruling party and state power consciously. Although social forces have generally grown in our country, as in most democracy countries, there is a serious "disconnect" between government and society. For a long time, the government has been charged with the triple task of strengthening regulation, ensuring drug safety, and promoting industrial development. The government has overly strengthened its own functions while neglecting the integration and cultivation of social resources, resulting in a serious path dependence of public participation in the governance of drug safety issues (Yang, 2017). This is the root cause of the fragile relationship and lack of trust between the Chinese government and society.

Secondly, although our government has made a lot of efforts to enhance public confidence in China's drug market and drug safety regulatory capacity, including encouraging social supervision, implementing a reporting reward system, and significantly increasing the cost of corporate violations. However, the experience of frequent drug safety incidents, under-reporting by local governments, and lagging information disclosure has destroyed the foundation of public trust. As the construction of drug safety risk communication institution is just the beginning, the cultivation of public trust will be extremely slow and difficult, and will often fall back or lost due to inadequate or inappropriate risk communication.

\section{Research Conclusion}

The adoption of the governance model undoubtedly points the way to the reform of the already increasingly weak government-underwritten drug safety regulatory system. Besides, in order to improve the effectiveness of drug safety governance, the participation of enterprises, social organizations, the public (professionals, such as doctors, pharmacists, etc.) or the media in governance requires a good framework of action and institutional environment as support (Sun, 2013), and cannot rely solely on the will or responsibility of each party. China's current governance preparation and socioeconomic development stage determine the cross-sector cooperative governance of drug safety can't be achieved 
overnight. It is inevitably a process of gradual development. As mentioned above, this paper constructs a "three-stage" drug safety governance development framework, which helps to recognize the current situation and development trend of drug safety governance more systematically in China, hoping to address theoretical research and practical challenges in a targeted manner. However, as the boundaries of each stage are not clear, there are overlaps and iterations. To ensure the smooth progress of governance reform, this paper designs specific policy actions based on a holistic perspective and recommends continuous improvement in the modernization construction of China drug safety governance system and capacity from various aspects such as governance norms, communication mechanisms, capacity cultivation, and cross-sector coordination.

\section{Reflections and Suggestions}

\subsection{Establishing Legal Norms for Collaborative Drug Safety Governance}

A series of activities related to multiple interests, such as formulation of drug registration standards, drug safety inspection, medical insurance access policy and centralized drug procurement policy should have a clear cooperative governance framework and rules to legitimize the governance power of public and private sectors. At the same time, the limits of collaborative governance must be rationally examined, otherwise it is likely to be degraded into a strategic response to administrative intervention or public opinion inducement (Zhang, 2015).

It is recommended that the boundaries of the government's duties and responsibilities, the content of corporate self-governance and the limits of social participation be clearly explained in the form of legal documents. Relevant departments establish governance norms covering all levels of government sectors and various regulatory measures. Through legal empowerment, nongovernmental subjects can truly participate in the consultation, decisionmaking and action process of drug safety governance policy, so as to prevent them from becoming "chosen people" and to promote the coordination of administrative regulation, industry self-governance and social co-governance. For example, the UK government classified drug safety matters into three levels of low, medium, and high risk based on the principles of risk governance. The scope of industry participation in governance has been formally defined through legal authorization such as the Health and Social Care Act and the Pharmacy Act (Chen, Wang, \& Sun, 2015). Specifically, it mainly empowers pharmaceutical enterprises and industry associations to govern themselves in low-risk change affairs and medium-risk matters such as drug advertising complaints and management of pharmacy compliance. This has helped to improve the efficiency of administrative resources and prevented the possibility of arbitrary enforcement by the UK Medicines and Healthcare products Regulatory Agency (MHRA). 


\subsection{Ensure Equal Communication between Governance Sectors}

Collaborative cross-sector governance is based on the equal dialogue among stakeholders, which is the key to enhancing trust and breaking down various barriers that prevent stakeholders from reaching consensus and joint action. To ensure equal communication, it is recommended that the government take full leadership and follow the principles of openness, transparency, and responsiveness: 1) Openness refers to increased accessibility. The government can invite experts and industry representatives to dialogue at appropriate points in the drug safety system design, evaluation and decision-making, with the aim of submitting evidence, discussing and improving the regime design and evaluate draft regime. 2) Transparency refers to making stakeholders aware of the process and considerations of drug safety system decision-making, such as publicizing government meeting minutes, flight inspection records, etc. on official websites, which can also be provided upon the request of society or market entities. Out of concern for confidentiality and proprietary information protection, full information disclosure may lead to some problems. However, as long as the rules are well designed, the public can usually tolerate the relative lack of transparency. 3) Responsiveness refers to the extent to which government actions have met the needs and expectations of stakeholders. For this purpose, it is necessary to establish a unobstructed information platform and feedback channels so that relevant information can be fed back to stakeholders in a timely manner. It is recommended that a comprehensive feedback platform for proceedings be established jointly with drug regulatory departments at all levels, drug audit agencies, inspection and testing and risk assessment centers. We use modern network systems such as wechat, microblogs and portals for instant communication to effectively respond to the voices of industry and society. The indicators of feedback efficiency and satisfaction will then be incorporated into the performance assessment of each department's government affairs.

\subsection{Cultivate the Capacity of Stakeholder Co-Governance at the Appropriate Time}

The universal and profound differences actually exisiting in knowledge structures, values, and interests among governance entities from different sectors make collaborative governance complex and unpredictable. Nurturing the substantive capacity of all sectors to participate in drug safety governance is essential to prevent "formal democracy" or "loose coupling".

Firstly, in order to make social organizations play the essential role in collaborative governance, it is recommended to help social organizations construct themselves through resource investment and policy support to eliminate their inertial dependence on the government (Duan, 2020). For example, highlight the advantages of industry associations in terms of social resources and professionalism, promote industry associations to undertake the necessary drug safety regulatory functions and explore new models of industry associations to partici- 
pate in the drug governance decision-making. Drug testing institutions and social testing institutions cooperate to establish a reasonable evaluation, stimulation and responsibility mechanisms, which also helps to improve the technical service capacity and professional quality of social testing institutions.

Secondly, fostering public-dominated social forces focuses on enhancing knowledge and consensus. In addition to public education to create a favorable environment for governance, substantive public participation requires feedback channels, consultative power, and opportunities to change government decisions. For example, make sure public participation influencing policy-making, seeking public suggestion in the design of participation pathways and providing the information needed for public participation to ensure that participation is conducted in a positive and meaningful way. Don't forget to inform the participating public about how their views will influence the final policy making. This is an inevitable choice to improve the democracy of decision-making and promote the realization of collaborative governance goals.

Finally, the key to the cultivation of corporate social responsibility lies in the establishment of a credit mechanism that runs through the entire life cycle and connects the whole regulatory chain before, during and after the event. The cultivation of corporate social responsibility should also strengthen the support and guarantee function of credit management. It is recommended to make full use of the national "Internet + supervision" and other systems to establish a risk prediction and early warning mechanism, so as to early detect and prevent crossregional drug safety risks. Utilize big data to dynamically monitor the manufacturing and distribution of pharmaceutical enterprises and their regular characteristics, and take the initiative to find and identify clues of violations. Where major problems are found in the sampling and inspection, the enterprise shall actively assume responsibility and disclose them properly on the Chinese government website or other channels.

\subsection{Establish a Multi-Level Cross-Sector Coordination Agency}

Strengthening cross-sector coordination is essential to improve the efficiency of drug safety governance decision-making and governance effectiveness. Specialized agencies in central and local government are proposed to address the practical challenges encountered in drug registration, manufacturing and distribution regulation in a targeted manner. For example, Japan employs administrative organizations to coordinate central and local governance. The United States, on the other hand, has established a federal-state relationship coordination section inside the FDA Office of Regulatory Affairs (ORA). Besides, it is suggested that a platform can be provided to support the stakeholders to reflect their demands through round tabled meetings, forums or the establishment of consultative organizations. Canada provides a consultation platform for officials at all levels, drug manufacturers and distributors, associations and chambers of commerce through holding regular round-table meetings. In addition, consideration can be 
given to dividing the country into a number of regulatory functional areas. Set up inspectorate dispatched agencies directly under the State Drug Administration to coordinate cross-regional matters and investigate to handle major drug safety cases. Convert section-based workflow to flat policy coordination.

\section{Discussion}

Since the research on drug safety governance is oriented toward public management or administration and has a certain level of difficulty and depth in understanding, the interviewees are mostly concentrated in government departments and policy research institutions. This research merely represents the opinions of special groups who have related experiences, thus with certain limitations. In the future, if the scope of the survey can be further expanded to other government departments or even private sector entities such as the press and media or pharmaceutical enterprises, it will probably enrich the connotation of the drug safety governance system.

\section{Fund Project}

National Social Science Foundation of China "International Comparative Research on Collaborative Governance of Food and Drug Safety" (15BZZ052).

\section{Conflicts of Interest}

The authors declare no conflicts of interest regarding the publication of this paper.

\section{References}

Agranoff, R. (2007). Managing within Networks. Georgetown University Press.

Agranoff, R., \& Mcguire, M. (2004). Collaborative Public Management: New Strategies for Local Governments. Georgetown University Press.

Ansell, C., \& Gash, A. (2008). Collaborative Governance in Theory and Practice. Journal of Public Administration Research \& Theory, 18, 543-571. https://doi.org/10.1093/jopart/mum032

Bryson, J. M., Crosby, B. C., \& Stone, M. M. (2006). The Design and Implementation of Cross-Sector Collaborations: Propositions Form the Literature. Public Administration Review, 66, 44-55. https://doi.org/10.1111/j.1540-6210.2006.00665.x

Cai, L. (2015). Collaborative Governance: A Solution to Complex Public Problems. Journal of Jinan (Philosophy and Social Science Edition), 37, 110-118.

Chen, Y. F., Wang, Q., \& Sun, X. F. (2015). UK Drug Regulatory Effectiveness Improvement Program and Its Inspirations. Pharmaceutical Herald, 34, 1261-1264.

Dai, H. (2013). Accelerate the Construction of Food and Drug Safety Social Governance Pattern. China Food and Drug Administration, 8, 28-29.

Duan, X. (2020). Constructive Dimensions and Co-Construction Strategies of Social Organization Participation in National Governance. Seeking, 5, 121-127.

Emerson, K., Nabatchi, T., \& Balogh S. (2012). An Integrative Framework for Collaborative Governance. Journal of Public Administration Research and Theory, 22, 1-29. https://doi.org/10.1093/jopart/mur011

Fan, P. (2019). Interdependence and Cooperation: State-Society Relations since the Reform 
and Opening-Up. Yunnan Social Science, 1, 29-36, 186.

Fierlbeck, K. (2010). Public Health and Collaborative Governance. Canadian Public Administration, 53, 1-19. https://doi.org/10.1111/j.1754-7121.2010.00110.x

Guo, D. J. (2016). Collaborative Governance Is a Governance Model That Meets the Real Needs of China. Political Science Research, 1, 61-70+126-127.

Himmelman, A. T. (1994). Communities Working Collaboratively for Change. In M. S. Herrman (Ed.), Resolving Conflict: Strategies for Local Government (pp. 27-47). County Management Association.

Hu, Y. L. (2014). From the Welfare to People's Livelihood Talking about the Change of Drug Safety Management System in New China. China Pharmaceutical Affairs, 9, 925-933.

Hu, Y. L., \& Lin, M. (2017). Looking beyond Regulation to Safety: Building a National Drug Safety Governance Regime. China Administration, 6, 115-120.

Huxham, C., \& Vangen, S. (2000). Leadership in the Shaping, and Implementation of Collaboration Agendas: How Things Happen in a (Not Quite) Joined-Up World. Academy of Management Journal, 43, 1159-1175.

Liang, X. F., Liu, J. D., Zhang, X. S. et al. (2020). Survey on the Impact of Changchun Changsheng Vaccine Incident on Parents' Attitude toward Vaccination of Children in Gansu Province. Primary Health Care in China, 34, 67-69.

Milward, H. B., \& Provan, K. G. A. (2006). Manager's Guide to Choosing and Using Collaborative Networks. IBM Center for the Business of Government.

Neto, P., Brandão, A., \& Cerqueira, A. (2008). The Impact of FDI, Cross-Border Mergers and Acquisitions, and Greenfield Investments on Economic Growth. The IUP Journal of Business Strategy, 7, 24-44.

Shen, W. X., \& Liu, C. (2017). Discussion on the Connotation, Meaning and Mechanism of Social Governance of Drug Safety in China. Law Journal, 38, 47-56.

Stiglitz, J., \& Song, H. L. (2002). Freedom, the Informed Right and Public Discourse-The Role of Transparency in Public Life. Global Law Review, 24, 263-273.

Sun, M. (2013). Research on the Constraints and Countermeasures of Social Governance of Food and Drug Safety. Journal of Chongqing University of Commerce and Industry (Social Science Edition), 30, 87-94.

The Free Dictionary by Farlex. https://idioms.thefreedictionary.com/the+driving+force

Thomson, A. M., \& Perry, J. L. (2006). Collaboration Processes: Inside the Black Box. Public Administration Review, 66, 20-32. https://doi.org/10.1111/j.1540-6210.2006.00663.x

Tian, P. J. (2013). Collaborative Governance: A Theoretical Research Framework and Analytical Model. Shanghai Jiao Tong University.

Tullock, G. (1980). Efficient Rent-Seeking. In J. Buchanan, R. Tollison, \& G. Tullock (Eds.), Toward a Theory of the Rent-Seeking Society (pp. 97-112). Texas A \& M Universty Press.

Yang, H. F. (2017). A Review of the Path from Administrative Supervision to Collaborative Governance of Drug Safety: An Examination Based on the Shandong Vaccine Incident. Journal of Tianjin Administrative College, 3, 8-15.

Yang, H. F. (2017). Drug Safety and its Governance Logic in the Perspective of Collaborative Governance. Executive Forum, 24, 118-123.

Zhang, G. Y. (2017). Analysis and Reflection on the Phenomenon of Professional Counterfeiters. Journal of Inspection and Quarantine, 27, 51-53

Zhang, Z. B. (2015). Discussion on the Generative Logic and Constructive Path of Collaborative Governance. China Administration, 1, 58-60. 